\title{
Evaluation of total flavonoid content of Labisia pumila leaves based on impedance measurements
}

\begin{abstract}
Herbal medicines have gained tremendous interest due to increasing awareness towards maintaining health through natural products. One of the important processes in herbal production is screening plants for phytochemical content as a standard quality assessment of herbal product. Phytochemical content analysis of herbal plants involves several complicated steps such as extraction, separation and identification. Current methods used for phytochemical content analysis are destructive, timeconsuming and require expensive instruments such as HPLC, UV-spectroscopy and GC-MS. In this work, a new approach on accessing phytochemical content of Labisia pumila (var. pumila) leaves using impedance measurement was evaluated. Impedance of L. pumila leaves was measured using a pair of ECG probe connected to an impedance analyzer board (AD5933 Analog Device) and to a computer in the frequency range from $100 \mathrm{~Hz}$ to $100 \mathrm{kHz}$. The total flavonoid content (TFC) was analyzed using standard extraction method and spectrophotometer for comparison. Results indicate that the leaf impedance measurement depended significantly on frequencies and had positive correlation with TFC. It was shown that impedance measurement is potentially useful to screen TFC in Labisia pumila leaves.
\end{abstract}

Keyword: Ficus deltoidea; Leaves; Mathematical models; Thin-layer drying 